Article

\title{
Self-Assembly of $\mathrm{Bi}_{2} \mathrm{Te}_{3}$-Nanoplate/Graphene-Nanosheet Hybrid by One-Pot Route and Its Improved Li-Storage Properties
}

\author{
Fangfang Tu, Jian Xie *, Gaoshao Cao and Xinbing Zhao
}

State Key Laboratory of Silicon Materials, Department of Materials Science and Engineering, Zhejiang University, Hangzhou 310027, China; E-Mails: fangfangtu1990@126.com (F.T.); gscao@zju.edu.cn (G.C.); zhaoxb@zju.edu.cn (X.Z.)

* Author to whom correspondence should be addressed; E-Mail: xiejian1977@zju.edu.cn; Tel.: +86-571-8795-2181; Fax: +86-571-8795-1451.

Received: 12 June 2012; in revised form: 5 July 2012 / Accepted: 10 July 2012 /

Published: 23 July 2012

\begin{abstract}
A sandwich structured $\mathrm{Bi}_{2} \mathrm{Te}_{3}$-nanoplates/graphene-nanosheet $\left(\mathrm{Bi}_{2} \mathrm{Te}_{3} / \mathrm{G}\right)$ hybrid has been synthesized by a facile in situ solvothermal route and has been investigated as a potential anode material for $\mathrm{Li}$-ion batteries. $\mathrm{Bi}_{2} \mathrm{Te}_{3}$ grows during the solvothermal process with the simultaneous reduction of graphite oxide into graphene. The in situ formation process of the hybrid has been investigated by X-ray diffraction and X-ray photoelectron spectra. The Li-storage mechanism and performance of $\mathrm{Bi}_{2} \mathrm{Te}_{3} / \mathrm{G}$ and bare $\mathrm{Bi}_{2} \mathrm{Te}_{3}$ have been studied by galvanostatic cycling and cyclic voltammetry. The $\mathrm{Bi}_{2} \mathrm{Te}_{3} / \mathrm{G}$ sandwich exhibits an obviously improved cycling stability compared to bare $\mathrm{Bi}_{2} \mathrm{Te}_{3}$. The enhancement in electrochemical performance can be attributed to the combined conducting, confining and dispersing effects of graphene for $\mathrm{Bi}_{2} \mathrm{Te}_{3}$ nanoplates and to the self-assembled sandwich structure.
\end{abstract}

Keywords: bismuth telluride; graphene; Li-ion batteries; sandwich

\section{Introduction}

Although carbon based materials are presently the dominant anodes in commercial Li-ion batteries, there is still a great challenge to develop alternative anode materials in order to meet the requirement of high-performance Li-ion batteries [1,2]. Alloy materials have been regarded as one of the most promising anodes for the next-generation Li-ion batteries because of their safe operating voltage and 
the large energy density, especially the large volumetric energy density due to the high density $[3,4]$. Among various elements that can form Li-alloys, Sb has received a special interest because of its appropriate alloying/de-alloying voltage (around $0.8 \mathrm{~V}$ vs. $\mathrm{Li} / \mathrm{Li}^{+}$) and relatively large Li-storage capacity (660 $\mathrm{mAh} \mathrm{g}^{-1}$ ) with the formation of $\mathrm{Li}_{3} \mathrm{Sb}$ composition [5]. However, the volume change is over $200 \%$ during the conversion from $\mathrm{Sb}$ to $\mathrm{Li}_{3} \mathrm{Sb}$ [6]. The volume change causes the cracking and crumbling of the particles, resulting in the loss of physical contact between the active particles and the current collector and the consequent capacity loss upon cycling.

Many measures have been taken to alleviate the volume changes for Sb during alloying/de-alloying processes. Previous work [7-10] showed that the cycling stability of metallic Sb can be improved by using Sb-based intermetallic compound $\mathrm{MSb}_{\mathrm{x}}$, where $\mathrm{M}$ is an electrochemically inert element and acts as the buffering matrix. The improvement in electrochemical performance could also be realized by using nanostructured materials [11-14] due the large surface area, short Li-ion diffusion path and increased mechanical strength. However, the nanoparticles tend to aggregate, also leading to the disconnection of active material with the current collector. An effective approach to overcome this problem is to immobilize the nanoparticles on a matrix. Carbon-based materials [15-18] are considered as the ideal matrices since they are electrically conductive and electrochemically active in addition to the buffering effect for the volume change.

Graphene, a flat monolayer of $\mathrm{sp}^{2}$-bonded carbon atoms [19], was also the ideal matrix because of its appealing properties such as high electronic conductivity [20], high specific surface area [21] and high mechanical strength [22]. Our previous work showed that the cycling stability of some Sb-based intermetallic compounds could be improved by forming nanocomposites with graphene [23,24]. Similar to $\mathrm{Sb}, \mathrm{Bi}$ in the same group can also electrochemically store $\mathrm{Li}$ by forming a $\mathrm{Li}_{3} \mathrm{Bi}$ composition [5,25-27]. So far, the effect of graphene on the electrochemical performance of Bi-based anodes has not been reported yet. Herein, an in situ solvothermal route was used to prepare the $\mathrm{Bi}_{2} \mathrm{Te}_{3}$-nanoplate/graphene-nanosheet $\left(\mathrm{Bi}_{2} \mathrm{Te}_{3} / \mathrm{G}\right)$, where Te can also reversibly store Li by forming $\mathrm{Li}_{2} \mathrm{Te}$ [27]. The results showed that an obvious improvement in cycling stability of $\mathrm{Bi}_{2} \mathrm{Te}_{3}$ could be realized by constructing a $\mathrm{Bi}_{2} \mathrm{Te}_{3} / \mathrm{G}$ hybrid with a sandwich structure.

\section{Results and Discussion}

Figure 1a shows the XRD patterns of $\mathrm{Bi}_{2} \mathrm{Te}_{3} / \mathrm{G}$ and bare $\mathrm{Bi}_{2} \mathrm{Te}_{3}$. For comparison, the standard diffraction peaks of $\mathrm{Bi}_{2} \mathrm{Te}_{3}$ are also given. All the diffraction peaks can be indexed to hexagonal $\mathrm{Bi}_{2} \mathrm{Te}_{3}$ (JCPDS No. 89-2009) for both $\mathrm{Bi}_{2} \mathrm{Te}_{3} / \mathrm{G}$ and bare $\mathrm{Bi}_{2} \mathrm{Te}_{3}$. The diffraction peaks of graphene that should appear at around $2 \theta=25{ }^{\circ} \mathrm{C}$ cannot be detected, suggesting that the restacking of graphene sheets after reduction was inhibited by uniformly loading $\mathrm{Bi}_{2} \mathrm{Te}_{3}$ plates between the graphene sheets. The graphene content is roughly estimated to be $11.5 \mathrm{wt} \%$ by the carbon content analysis.

To check the reduction status of GO during the solvothermal reactions, C1s XPS spectra of GO and $\mathrm{Bi}_{2} \mathrm{Te}_{3} / \mathrm{G}$ are analyzed as shown in Figure $1 \mathrm{~b}$. The spectra can be fitted by four peaks for different forms of carbons: non-oxygenated carbon $(\mathrm{C}-\mathrm{C}, 285.6 \mathrm{eV}$ and $\mathrm{C}=\mathrm{C}, 284.8 \mathrm{eV})$, carbon in $\mathrm{C}-\mathrm{O}$ bonds $(286.3 \mathrm{eV})$, carbonyl carbon $(\mathrm{C}=\mathrm{O}, 287.6 \mathrm{eV})$ and carboxylate carbon $(\mathrm{O}-\mathrm{C}=\mathrm{O}, 289.0 \mathrm{eV})$ [28]. After the solvothermal reactions, the peak intensity of the oxygenated carbons $(\mathrm{C}-\mathrm{O}, \mathrm{C}=\mathrm{O}, \mathrm{O}-\mathrm{C}=\mathrm{O})$ shows an obvious decrease, indicating the reduction of GO into graphene. Figure 1c gives the O1s XPS 
spectra of the hybrid. The broad peak at $532.2 \mathrm{eV}$ is assigned to the residual oxygen-containing groups such as $-\mathrm{COOH}$ and $-\mathrm{OH}$ [29], which agrees with the result of $\mathrm{C} 1 \mathrm{~s}$ spectra. From the XRD and XPS analyses, it can be concluded that a $\mathrm{Bi}_{2} \mathrm{Te}_{3} / \mathrm{G}$ hybrid has formed with the simultaneous formation $\mathrm{Bi}_{2} \mathrm{Te}_{3}$ and reduction of $\mathrm{GO}$ during the one-step solvothermal process.

Figure 1. (a) XRD of $\mathrm{Bi}_{2} \mathrm{Te}_{3} / \mathrm{G}$ and bare $\mathrm{Bi}_{2} \mathrm{Te}_{3}$; (b) $\mathrm{C} 1 \mathrm{~s}$ XPS of $\mathrm{GO}$ and $\mathrm{Bi}_{2} \mathrm{Te}_{3} / \mathrm{G}$; (c) O1s XPS of $\mathrm{Bi}_{2} \mathrm{Te}_{3} / \mathrm{G}$.
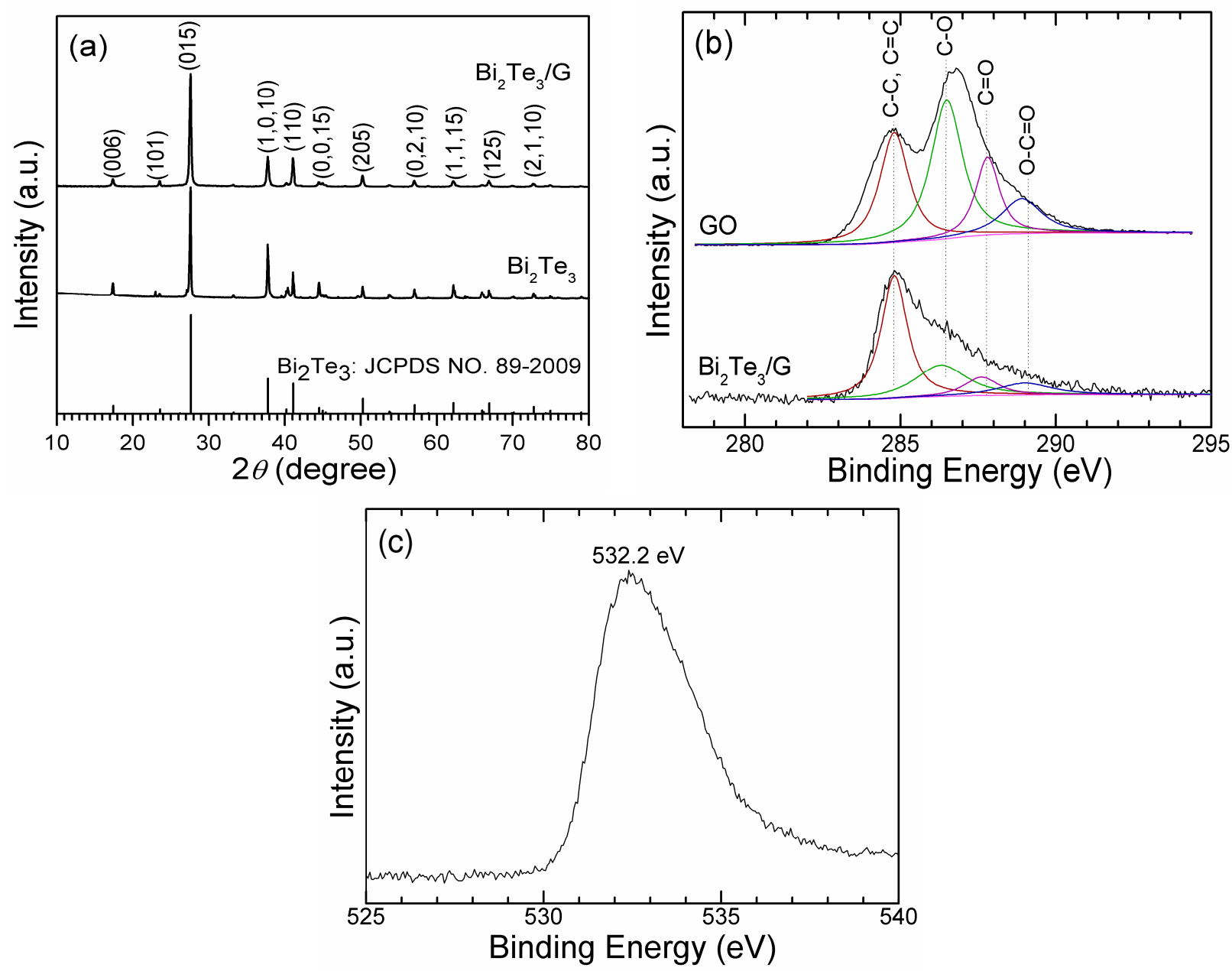

Figure 2a shows the SEM image of bare $\mathrm{Bi}_{2} \mathrm{Te}_{3}$ prepared by the solvothermal route without adding GO in the precursors. Generally, the sample exhibits a hexagonal plate shape with a size of around 0.5-3 $\mu \mathrm{m}$. However, smaller sized broken plates with an irregular shape can also be observed. The thickness of the plates is roughly estimated to be $50-100 \mathrm{~nm}$ from some vertically (or partially vertically) aligned plates denoted by the arrows. Figure $2 b$ shows the SEM image of the $\mathrm{Bi}_{2} \mathrm{Te}_{3} / \mathrm{G}$ hybrid. It is obvious from the transparent graphene that $\mathrm{Bi}_{2} \mathrm{Te}_{3}$ plates are located between the graphene sheets. The size of the $\mathrm{Bi}_{2} \mathrm{Te}_{3}$ plates is below $2 \mu \mathrm{m}$. A three-dimensional (3D) sandwich structure is thus constructed by alternatively arranged graphene layer and $\mathrm{Bi}_{2} \mathrm{Te}_{3}$ layer as clearly indicated by the arrows. The transparent nature of the graphene layer suggests that it is rather thin, composed probably of single or few layers of graphene sheets.

The microstructure of $\mathrm{Bi}_{2} \mathrm{Te}_{3} / \mathrm{G}$ was further characterized by TEM as shown in Figure $2 \mathrm{c}$. Note that nearly all of the $\mathrm{Bi}_{2} \mathrm{Te}_{3}$ plates are anchoring on graphene without forming free $\mathrm{Bi}_{2} \mathrm{Te}_{3}$ plates even after 
vigorous ultrasonication. The wrinkles and folded edges of graphene indicate that the graphene layer is rather thin, which agrees with the SEM observation. The enlarged view of the circled part in Figure 2c is presented in Figure 2d. The overlapping of the $\mathrm{Bi}_{2} \mathrm{Te}_{3}$ plates can be observed from Figure $2 \mathrm{~d}$, from which the transparent nature of the $\mathrm{Bi}_{2} \mathrm{Te}_{3}$ plate is evident. From a vertically aligned plate, the thickness of the plate is estimated to be $15 \mathrm{~nm}$, which is much smaller compared with that of bare $\mathrm{Bi}_{2} \mathrm{Te}_{3}$. The thickness of the $\mathrm{Bi}_{2} \mathrm{Te}_{3}$ plates is in the range of $10-20 \mathrm{~nm}$ after observing some plates at the edges or defect sites of graphene. It is worth noting that the number of the $\mathrm{Bi}_{2} \mathrm{Te}_{3}$ plates with a regular hexagon is much smaller compared with that of bare $\mathrm{Bi}_{2} \mathrm{Te}_{3}$ plates. It is believed that the irregular shape and small thickness of the $\mathrm{Bi}_{2} \mathrm{Te}_{3}$ plates in $\mathrm{Bi}_{2} \mathrm{Te}_{3} / \mathrm{G}$ are caused by the inhibited diffusion and re-crystallization of small sized $\mathrm{Bi}_{2} \mathrm{Te}_{3}$ particles due to the pinning effect of the defects and the oxygen-containing groups in graphene [30]. The presence of the residual oxygen-containing groups can be confirmed by XPS shown in Figure 1b,c.

Figure 2. (a) SEM image of bare $\mathrm{Bi}_{2} \mathrm{Te}_{3}$; (b) SEM image of $\mathrm{Bi}_{2} \mathrm{Te}_{3} / \mathrm{G}$ hybrid; (c) TEM image of $\mathrm{Bi}_{2} \mathrm{Te}_{3} / \mathrm{G}$ hybrid; (d) the enlarged view of the circled part in (c).
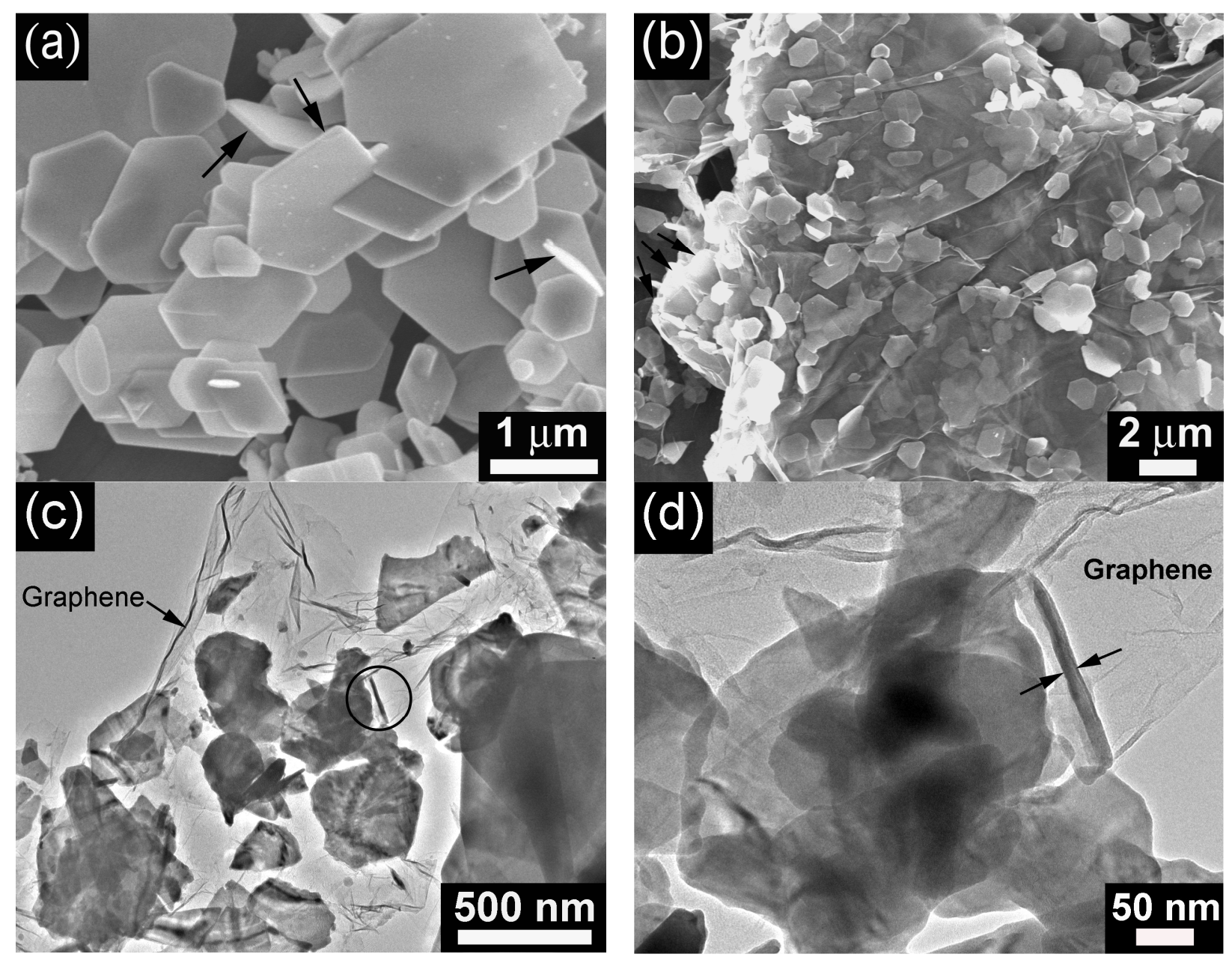

In Figure 3, CV plots of $\mathrm{Bi}_{2} \mathrm{Te}_{3} / \mathrm{G}$ and $\mathrm{Bi}_{2} \mathrm{Te}_{3}$ were measured to clarify the electrochemical reaction mechanism of $\mathrm{Bi}_{2} \mathrm{Te}_{3}$ with $\mathrm{Li}$. As seen in Figure 3a, the reaction $\mathrm{Bi}_{2} \mathrm{Te}_{3}$ with $\mathrm{Li}$ exhibits a multi-step mechanism, evidenced by the multi-peak feature of the CV plots. During the first cathodic scan, three reduction peaks, located at $2.0,1.25$, and $0.6 \mathrm{~V}$, respectively, appear as indicated by the black line in 
Figure 3a. The small peak at $2.0 \mathrm{~V}$ is related possibly to the insertion reaction of $\mathrm{Li}$ ion into layered $\mathrm{Bi}_{2} \mathrm{Te}_{3}$ without significantly destroying its crystal structure [31]. The peak at $1.2 \mathrm{~V}$ corresponds to the lithiation reaction of $\mathrm{Te}$ by forming $\mathrm{Li}_{2} \mathrm{Te}\left(2 \mathrm{Li}+\mathrm{Te} \rightarrow \mathrm{Li}_{2} \mathrm{Te}\right)$ [27], and the peak at $0.6 \mathrm{~V}$ is associated with the reaction of $\mathrm{Bi}$ with $\mathrm{Li}$ to form $\mathrm{Li}_{3} \mathrm{Bi}\left(3 \mathrm{Li}+\mathrm{Bi} \rightarrow \mathrm{Li}_{3} \mathrm{Bi}\right)$ [5,26,27]. During the second cathodic scan, the peak at $2.0 \mathrm{~V}$ almost disappears, the peak at $0.6 \mathrm{~V}$ is shifted to a higher value of $0.7 \mathrm{~V}$ (A'), while the peak at $1.2 \mathrm{~V}$ is divided into two peaks, B' and $\mathrm{C}^{\prime}$, located at 1.35 and $1.65 \mathrm{~V}$, respectively. The division of the peak means that the reaction of Te with Li occurs via a two-step mechanism by forming $\mathrm{LiTe}_{3}$ and $\mathrm{Li}_{2} \mathrm{Te}$ successively, both of which are stable phases at room temperature [32]. The lower peak potential in the first cathodic scan compared with those in the subsequent scans is due to the additional energy required for the displacement reactions of $\mathrm{Bi}_{2} \mathrm{Te}_{3}$ upon $\mathrm{Li}$ uptake [4]. This also means that structure of $\mathrm{Bi}_{2} \mathrm{Te}_{3}$ cannot be recovered after the anodic scan [27].

Note that three oxidation peaks (A, B, and C), at 1.0, 1.8 and $1.9 \mathrm{~V}$, respectively, appear during the anodic scans, corresponding to the successive de-lithiation reactions of $\mathrm{Li}_{3} \mathrm{Bi}$ (peak $\mathrm{A}$ ) and $\mathrm{Li}_{2} \mathrm{Te}$ (peak B and peak C). The CV plots of bare $\mathrm{Bi}_{2} \mathrm{Te}_{3}$ are also given for comparison as seen in Figure $3 \mathrm{~b}$. The plots of bare $\mathrm{Bi}_{2} \mathrm{Te}_{3}$ display a similar feature as those of $\mathrm{Bi}_{2} \mathrm{Te}_{3} / \mathrm{G}$ except that the peak intensity decreases more rapidly with scans, indicative of its lower reversibility. The relatively high reversibility of $\mathrm{Bi}_{2} \mathrm{Te}_{3} / \mathrm{G}$ can be attributed to the incorporation of graphene that improves the electrode kinetics and keeps the electrode integrity.

Figure 3. $\mathrm{CV}$ plots of (a) $\mathrm{Bi}_{2} \mathrm{Te}_{3} / \mathrm{G}$; and (b) $\mathrm{Bi}_{2} \mathrm{Te}_{3}$ scanned at $0.1 \mathrm{mV} \mathrm{s}^{-1}$.
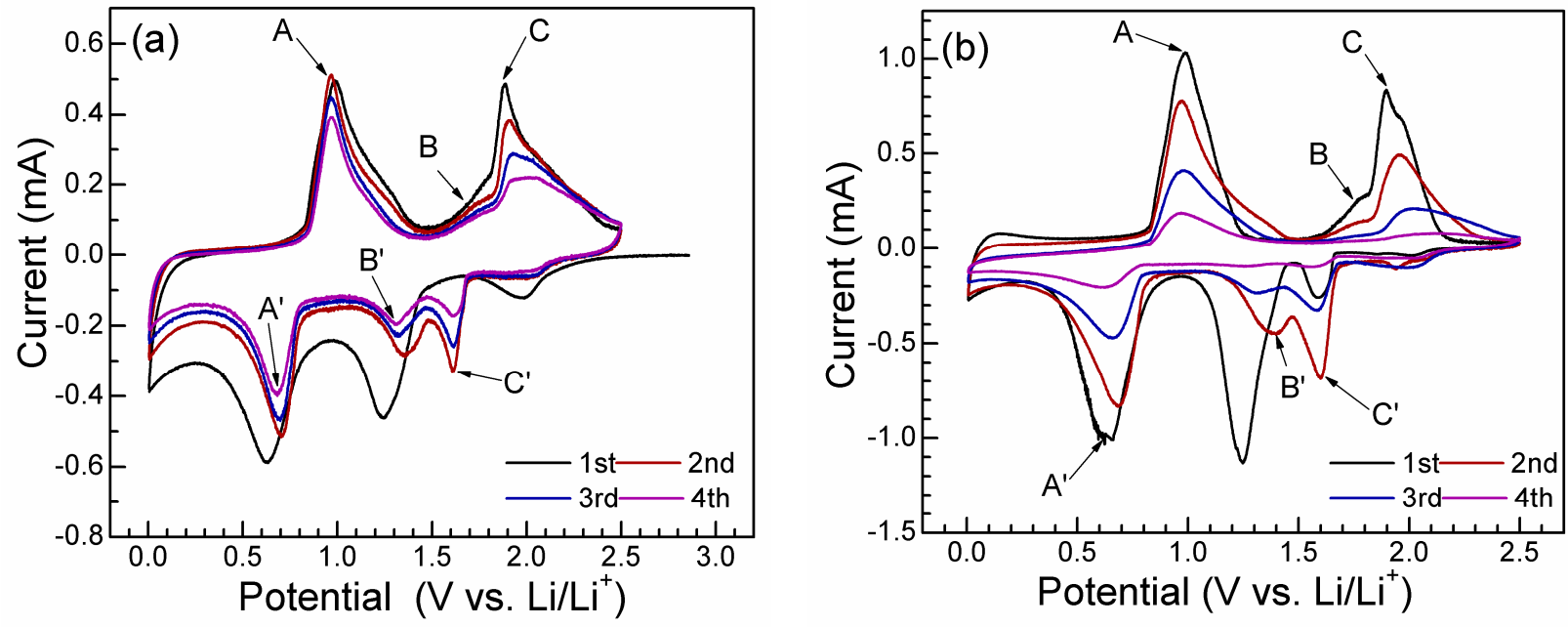

Figure $4 \mathrm{a}$ shows the chare-discharge curves of $\mathrm{Bi}_{2} \mathrm{Te}_{3}$ and $\mathrm{Bi}_{2} \mathrm{Te}_{3} / \mathrm{G}$ at $50 \mathrm{~mA} \mathrm{~g}^{-1}$ at various cycles. $\mathrm{Bi}_{2} \mathrm{Te}_{3} / \mathrm{G}$ hybrid gives a first discharge (Li-uptake) capacity of $731 \mathrm{mAh} \mathrm{g}^{-1}$ and a first charge (Li-extraction) capacity of $481 \mathrm{mAh} \mathrm{g}^{-1}$. The first irreversible capacity can be attributed to the reduction decomposition of the electrolyte and the formation of the solid state interface (SEI) layer. Successive potential plateaus can be seen during the charge-discharge cycling, which correspond to the current peaks in the $\mathrm{CV}$ plots. The appearance of the potential plateaus is due to the two-phase coexistence of original phase ( $\mathrm{Te}$ or $\mathrm{Bi}$ ) and the Li-alloys ( $\mathrm{Li}-\mathrm{Te}$ or $\mathrm{Li}-\mathrm{Bi}$ alloys). As shown in the figure, bare $\mathrm{Bi}_{2} \mathrm{Te}_{3}$ exhibits lower charge-discharge capacities compared with $\mathrm{Bi}_{2} \mathrm{Te}_{3} / \mathrm{G}$. The theoretical maximum capacity of $\mathrm{Bi}_{2} \mathrm{Te}_{3}$ is $401 \mathrm{mAh} \mathrm{g}^{-1}$, related to the formation of $\mathrm{Li}_{2} \mathrm{Te}$ and $\mathrm{Li}_{3} \mathrm{Bi}$. 
Considering the fact that graphene itself shows a relatively low capacity of around $300 \mathrm{mAh} \mathrm{g}^{-1}$, as reported in our previous work [33], the theoretical capacity of $\mathrm{Bi}_{2} \mathrm{Te}_{3} / \mathrm{G}$ should be lower than that of bare $\mathrm{Bi}_{2} \mathrm{Te}_{3}$. The high yieldable of $\mathrm{Bi}_{2} \mathrm{Te}_{3} / \mathrm{G}$ is possibly due to the synergistic effect between $\mathrm{Bi}_{2} \mathrm{Te}_{3}$ and graphene. On one hand, as discussed above, the presence of graphene can restrain the crystal growth of $\mathrm{Bi}_{2} \mathrm{Te}_{3}$, which is favorable for rapid $\mathrm{Li}$ ion diffusion within the active material. On the other hand, the separator effect of $\mathrm{Bi}_{2} \mathrm{Te}_{3}$ plates for graphene sheets maximizes the exposure of the graphene surface to the electrolyte, especially for the edges and vacancies on graphene. The edges and vacancies can supply additional sites for $\mathrm{Li}$ storage [34]. Note that $\mathrm{Bi}_{2} \mathrm{Te}_{3} / \mathrm{G}$ shows a progressive polarization upon cycling, but the extent is smaller than bare $\mathrm{Bi}_{2} \mathrm{Te}_{3}$ owing to the presence of the conductive graphene.

Figure $4 \mathrm{~b}$ compares the cycling stability between bare $\mathrm{Bi}_{2} \mathrm{Te}_{3}$ and $\mathrm{Bi}_{2} \mathrm{Te}_{3} / \mathrm{G}$ charged at 50 and $200 \mathrm{~mA} \mathrm{~g}^{-1}$ and discharged at $50 \mathrm{~mA} \mathrm{~g}^{-1}$. Note that $\mathrm{Bi}_{2} \mathrm{Te}_{3} / \mathrm{G}$ demonstrates an obviously slower capacity fade compared to bare $\mathrm{Bi}_{2} \mathrm{Te}_{3}$. After 50 cycles at $200 \mathrm{~mA} \mathrm{~g}^{-1}$ (about $0.5 \mathrm{C}$ ), a charge capacity of $158 \mathrm{mAh} \mathrm{g}^{-1}$ can be retained for $\mathrm{Bi}_{2} \mathrm{Te}_{3} / \mathrm{G}$. In contrast, the charge capacity of bare $\mathrm{Bi}_{2} \mathrm{Te}_{3}$ drops rapidly to $33 \mathrm{mAh} \mathrm{g}^{-1}$. The $\mathrm{Bi}_{2} \mathrm{Te}_{3} / \mathrm{G}$ hybrid also shows improved cycling stability compared with $\mathrm{Bi}_{2} \mathrm{Te}_{3}$-graphite composite [27] and other Bi-based anodes [25,26]. The enhanced cycling stability is attributed to the buffering effect of graphene that alleviates the large volume changes and the confinement effect of graphene that restrains the aggregation of the $\mathrm{Bi}_{2} \mathrm{Te}_{3}$ plates, in addition to offering effective conducting networks. The 3D sandwich structure also facilitates the Li-ion diffusion within the free space and across the electrode/electrolyte interface. In addition, the free space within the sandwich also affords additional room to buffer the volume changes. It should be stressed that the long-term cycling stability of the $\mathrm{Bi}_{2} \mathrm{Te}_{3} / \mathrm{G}$ hybrid is not satisfactory yet owing to the intrinsic large volume changes of the $\mathrm{Bi}_{2} \mathrm{Te}_{3}$ during alloying/de-alloying processes. However, it is clear that graphene plays an important role in enhancing the electrochemical properties of $\mathrm{Bi}_{2} \mathrm{Te}_{3}$. It also should be noted that the large-scaled of $\mathrm{Bi}_{2} \mathrm{Te}_{3} / \mathrm{G}$ is not favored due to the toxicity, price, and resource scarcity of $\mathrm{Bi}$ and Te. Nevertheless, it shows promising application in micro-batteries due to the possibility of micro processing of graphene and $\mathrm{Bi}_{2} \mathrm{Te}_{3}$.

Figure 4. (a) Voltage profiles; and (b) cycling stability of $\mathrm{Bi}_{2} \mathrm{Te}_{3} / \mathrm{G}$ and $\mathrm{Bi}_{2} \mathrm{Te}_{3}$.
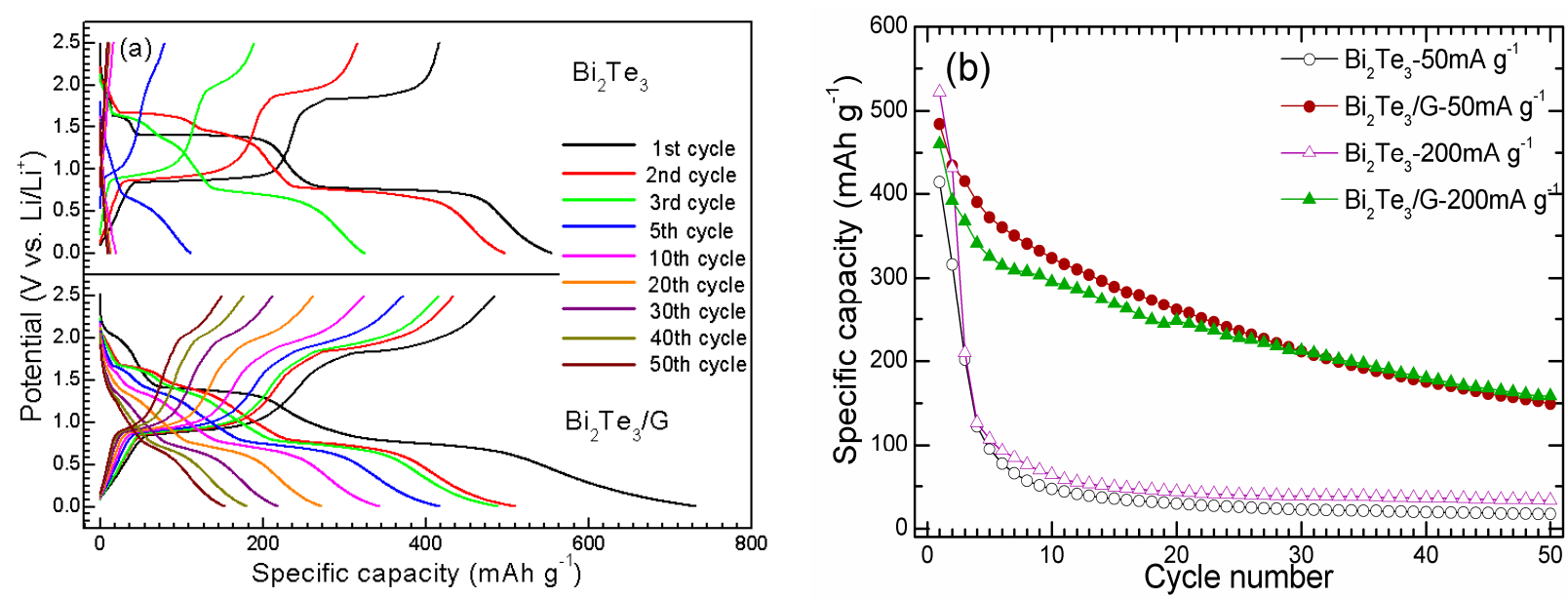


\section{Experimental Section}

\subsection{Preparation of $\mathrm{Bi}_{2} \mathrm{Te}_{3}$-Nanoplate/Graphene-Nanosheet $\left(\mathrm{Bi}_{2} \mathrm{Te}_{3} / G\right)$ Nanohybrid}

Graphite oxide (GO, $80 \mathrm{mg}$ ), prepared by a modified Hummer's method [35], was added into $40 \mathrm{~mL}$ of ethylene glycol (EG) and sonicated for $24 \mathrm{~h}$ to obtain a sufficiently exfoliated GO suspension. Then, $1 \mathrm{mmol}$ of $\mathrm{BiCl}_{3}, 1.5 \mathrm{mmol}$ of $\mathrm{Na}_{2} \mathrm{TeO}_{3}$ and $0.4 \mathrm{~g}$ of $\mathrm{NaOH}$ was added to the above suspension with sonication. After stirring for $12 \mathrm{~h}$, the mixed solution was then transferred to a Teflon-lined stainless steel autoclave $(100 \mathrm{~mL})$ and heated in an electric oven at $180{ }^{\circ} \mathrm{C}$ for $24 \mathrm{~h}$. The as-obtained product was collected by centrifugation, washed with deionized water and absolute ethanol for several times and dried at $40{ }^{\circ} \mathrm{C}$ under vacuum for $10 \mathrm{~h}$. Bare $\mathrm{Bi}_{2} \mathrm{Te}_{3}$ was also synthesized using a similar method without adding GO.

\subsection{Materials Characterization}

The X-ray diffraction (XRD) patterns were obtained on a Rigaku D/Max-2550pc powder diffractometer using $\mathrm{Cu} \mathrm{K} \mathrm{K}_{\alpha}$ radiation $(\lambda=0.1541 \mathrm{~nm})$. X-ray photoelectron spectra (XPS) were collected on a KRATOS AXIS ULTRA-DLD spectrometer with a monochromatic $\mathrm{Al} \mathrm{K}_{\alpha}$ radiation $(\mathrm{h} v=1486.6 \mathrm{eV})$. The morphologies of the products were observed by field emission scanning electron microscopy (FE-SEM) on a FEI-sirion microscope and transmission electron microscopy (TEM) on a JEM 2100F microscope. The carbon content analysis was conducted on a Flash EA 1112 tester.

\subsection{Electrochemical Measurements}

The electrochemical measurements of $\mathrm{Bi}_{2} \mathrm{Te}_{3} / \mathrm{G}$ and $\mathrm{Bi}_{2} \mathrm{Te}_{3}$ were performed with a half-cell configuration using CR2025-type coin cells. The working electrodes were prepared by spreading a slurry composed of $75 \mathrm{wt} \%$ active material $\left(\mathrm{Bi}_{2} \mathrm{Te}_{3} / \mathrm{G}\right.$ or $\left.\mathrm{Bi}_{2} \mathrm{Te}_{3} / \mathrm{G}\right), 15 \mathrm{wt} \%$ poly(vinylidene fluoride) (PVDF) and $10 \mathrm{wt} \%$ acetylene black onto $\mathrm{Ni}$ foam followed by drying at $100{ }^{\circ} \mathrm{C}$ for $12 \mathrm{~h}$ under vacuum. The loading mass of the active material is around $2 \mathrm{mg}$. The cells were assembled in an Ar-filled glove box using Li foil as the counter electrode and Celgard 2300 membrane as the separator. The electrolyte used was $1 \mathrm{M} \mathrm{LiPF}_{6}$ in ethylene carbonate (EC)/dimethyl carbonate (DMC) (volume ratio 1:1). The cells were galvanostatically charged-discharged at $50 \mathrm{~mA} \mathrm{~g}^{-1}$ between 0.005 and $2.5 \mathrm{~V}$ vs. $\mathrm{Li} / \mathrm{Li}^{+}$on a Neware battery tester (Shenzhen, China). The specific capacity of $\mathrm{Bi}_{2} \mathrm{Te}_{3} / \mathrm{G}$ was calculated based on the total weight of $\mathrm{Bi}_{2} \mathrm{Te}_{3}$ and graphene. Cyclic voltammetry (CV) tests were carried out on an Arbin BT2000 system at a scan rate of $0.1 \mathrm{mV} \mathrm{s}{ }^{-1}$ between 0.005 and $2.5 \mathrm{~V} \mathrm{vs.} \mathrm{Li} / \mathrm{Li}^{+}$. All of the electrochemical measurements were carried out at room temperature.

\section{Conclusions}

The $\mathrm{Bi}_{2} \mathrm{Te}_{3} / \mathrm{G}$ sandwich has been prepared by an in situ route with alternatively arranged $\mathrm{Bi}_{2} \mathrm{Te}_{3}$ nanoplates and graphene nanosheets. The diffusion and re-crystallization of $\mathrm{Bi}_{2} \mathrm{Te}_{3}$ in $\mathrm{Bi}_{2} \mathrm{Te}_{3} / \mathrm{G}$ are inhibited due to presence of oxygen-containing groups and defects on graphene, leading to more irregular shape and smaller thickness of $\mathrm{Bi}_{2} \mathrm{Te}_{3}$ in $\mathrm{Bi}_{2} \mathrm{Te}_{3} / \mathrm{G}$ compared with those in bare $\mathrm{Bi}_{2} \mathrm{Te}_{3}$. Both $\mathrm{Bi}_{2} \mathrm{Te}_{3} / \mathrm{G}$ and $\mathrm{Bi}_{2} \mathrm{Te}_{3}$ exhibit a multi-step lithiation mechanism. The $\mathrm{Bi}_{2} \mathrm{Te}_{3} / \mathrm{G}$ hybrid can yield a 
higher-than-the-theoretical charge capacity of $\mathrm{mAh} \mathrm{h}^{-1}$ at $50 \mathrm{~mA} \mathrm{~g}^{-1}$ due to the synergistic effect between $\mathrm{Bi}_{2} \mathrm{Te}_{3}$ and graphene. The $\mathrm{Bi}_{2} \mathrm{Te}_{3} / \mathrm{G}$ hybrid shows an obviously improved cycling stability compared with bare $\mathrm{Bi}_{2} \mathrm{Te}_{3}$. The improved cycling stability is attributed to the $3 \mathrm{D}$ sandwich structure, where graphene not only buffers the volume changes but also immobilizes $\mathrm{Bi}_{2} \mathrm{Te}_{3}$ nanoplates, in addition to offering effective conducting networks. The unique sandwich structure also facilitates Li-ion diffusion at the electrode/electrolyte interface and within the free space of the sandwich.

\section{Acknowledgments}

This work was supported by the National Natural Science Foundation of China (No. 51101139), the Ph.D. Programs Foundation of Ministry of Education of China (No. 20100101120024), the Foundation of Education Office of Zhejiang Province (No. Y201016484), the Qianjiang Talents Project of Science Technology Department of Zhejiang Province (2011R10021), and Key Science and Technology Innovation Team of Zhejiang Province under grant number 2010R50013.

\section{References}

1. Tarascon, J.M.; Armand, M. Issues and challenges facing rechargeable lithium batteries. Nature 2001, 414, 359-367.

2. Poizot, P.; Laruelle, S.; Grugeon, S.; Dupont, L.; Tarascon, J.M. Nano-sized transition-metal oxides as negative-electrode materials for lithium-ion batteries. Nature 2000, 407, 496-499.

3. Tirado, J.L. Inorganic materials for the negative electrode of lithium ion batteries: State-of-the-art and future prospects. Mater. Sci. Eng. R 2003, 40, 103-136.

4. Zhang, W.J. Lithium insertion/extraction mechanism in alloy anodes for lithium-ion batteries. J. Power Sources 2011, 196, 877-887.

5. Huggins, R.A. Lithium alloy negative electrodes. J. Power Sources 1999, 81-82, 13-19.

6. Obrovac, M.N.; Christensen, L.; Le, D.B.; Dahn, J.R. Alloy design for lithium-ion battery anodes. J. Electrochem. Soc. 2007, 154, A849-A855.

7. Alcántara, R.; Fernández-Madrigal, F.J.; Lavela, P.; Tirado, J.L.; Jumas J.C.; Olivier-Fourcade, J. Electrochemical reaction of lithium with the $\mathrm{CoSb}_{3}$ skutterudite. J. Mater. Chem. 1999, 9, 2517-2521.

8. Park, C.M.; Sohn, H.J. Antimonides $\left(\mathrm{FeSb}_{2}, \mathrm{CrSb}_{2}\right)$ with orthorhombic structure and their nanocomposites for rechargeable Li-ion batteries. Electrochim. Acta 2010, 55, 4987-4994.

9. Villevieille, C.; Ionica-Bousquet, C.M.; Ducourant, B.; Jumas, J.C.; Monconduit, L. NiSb 2 as negative electrode for Li-ion batteries: An original conversion reaction. J. Power Sources 2007, $172,388-394$.

10. Park, C.M.; Sohn, H.J. Electrochemical characteristics of $\mathrm{TiSb}_{2}$ and $\mathrm{Sb} / \mathrm{TiC} / \mathrm{C}$ nanocomposites as anodes for rechargeable Li-ion batteries. J. Electrochem. Soc. 2010, 157, A46-A49.

11. Xie, J.; Zhao, X.B.; Cao, G.S.; Zhao, M.J.; Su, S.F. Solvothermal synthesis and electrochemical performances of nanosized $\mathrm{CoSb}_{3}$ as anode materials for Li-ion batteries. J. Power Sources $\mathbf{2 0 0 5}$, $140,350-354$.

12. Xie, J.; Zhao, X.B.; Cao, G.S.; Zhong, Y.D.; Zhao, M.J.; Tu, J.P. Solvothermal synthesis of nanosized $\mathrm{CoSb}_{2}$ alloy anode for Li-ion batteries. Electrochim. Acta 2005, 50, 1903-1907. 
13. Sarakonsri, T.; Johnson, C.S.; Hackney, S.A.; Thackeray, M.M. Solution route synthesis of InSb, $\mathrm{Cu}_{6} \mathrm{Sn}_{5}$ and $\mathrm{Cu}_{2} \mathrm{Sb}$ electrodes for lithium batteries. J. Power Sources 2006, 153, 319-327.

14. Kim, H.; Cho, J. Template synthesis of hollow Sb nanoparticles as a high-performance lithium battery anode material. Chem. Mater. 2008, 20, 1679-1681.

15. Chen, W.X.; Lee, J.Y.; Liu, Z.L. The nanocomposites of carbon nanotube with $\mathrm{Sb}$ and $\mathrm{SnSb}_{0.5}$ as Li-ion battery anodes. Carbon 2003, 41, 959-966.

16. Hassoun, J.; Derrien, G.; Panero, S.; Scrosati, B. The role of the morphology in the response of $\mathrm{Sb}-\mathrm{C}$ nanocomposite electrodes in lithium cells. J. Power Sources 2008, 183, 339-343.

17. He, Y.; Huang, L.; Li, X.; Xiao, Y.; Xu, G.L.; Li, J.T.; Sun, S.G. Facile synthesis of hollow $\mathrm{Cu}_{2} \mathrm{Sb} @ \mathrm{C}$ core-shell nanoparticles as a superior anode material for lithium ion batteries. J. Mater. Chem. 2011, 21, 18517-18519.

18. Applestone, D.; Yoon, S.; Manthiram, A. $\mathrm{Mo}_{3} \mathrm{Sb}_{7}-\mathrm{C}$ composite anodes for Lithium-ion batteries. $J$. Phys. Chem. C 2011, 115, 18909-18915.

19. Novoselov, K.S.; Geim, A.K.; Morozov, S.V.; Jiang, D.; Zhang, Y.; Dubonos, S.V.; Grigorieva, I. V.; Firsov, A.A. Electric filed effect in atomically thin carbon films. Science 2004, 306, 666-669.

20. Park, S.; An, J.H.; Jung, I.W.; Piner, R.D.; An, S.J.; Li, X.S.; Velamakanni, A.; Ruoff, R.S. Colloidal suspensions of highly reduced graphene oxide in a wide variety of organic solvents. Nano Lett. 2009, 9, 1593-1597.

21. Stoller, M.D.; Park, S.; Zhu, Y.W.; An, J.H.; Ruoff, R.S. Graphene-based ultracapacitor. Nano Lett. 2008, 8, 3498-3502.

22. Lee, C.; Wei, X.D.; Kysar, J.W.; Hone, J. Measurement of the elastic properties and intrinsic strength of monolayer graphene. Science 2008, 321, 385-388.

23. Xie, J.; Zheng, Y.X.; Pan, R.J.; Liu, S.Y.; Song, W.T.; Cao, G.S.; Zhu, T.J.; Zhao, X.B. Sb-based alloy $\left(\mathrm{NiSb}, \mathrm{FeSb}_{2}\right)$ nanoparticles decorated graphene prepared by one-step solvothermal route as anode for Li-ion batteries. Int. J. Electrochem. Sci. 2011, 6, 4811-4821.

24. Zheng, Y.X.; Xie, J.; Liu, S.Y.; Song, W.T.; Cao, G.S.; Zhu, T.J.; Zhao, X.B. Self-assembly of Co-Sb-nanocrystal/graphene hybrid nanostructure with improved Li-storage properties via a facile in situ solvothermal route. J. Power Sources 2012, 202, 276-283.

25. Crosnier, O.; Devaux, X.; Brousse, T.; Fragnaud, P.; Schleich, D.M. Influence of particle size and matrix in "metal" anodes for Li-ion cells. J. Power Sources 2001, 97-98, 188-190.

26. Pérez-Flores, J.C.; Kuhn, A.; García-Alvarado, F. Electrochemical performances of $\mathrm{BiSbO}_{4}$ as electrode material for lithium batteries. J. Power Sources 2008, 182, 365-369.

27. Zhao, X.B.; Cao, G.S.; Lv, C.P.; Zhang, L.J.; Hu, S.H.; Zhu, T.J.; Zhou, B.C. Electrochemical properties of some $\mathrm{Sb}$ or Te based alloys for candidate anode materials of lithium-ion batteries. J. Alloys Compd. 2001, 315, 265-269.

28. Shin, H.J.; Kim, K.K.; Benayad, A.; Yoon, S.M.; Park, H.K.; Jung, I.S.; Jin, M.H.; Jeong, H.K.; Kim, J.M.; Choi, J.Y.; Lee, Y.H. Efficient reduction of graphite oxide by sodium borohydride and its effect on electrical conductance. Adv. Funct. Mater. 2009, 19, 1987-1992.

29. Wu, Z.S.; Ren, W.C.; Wen, L.; Gao, L.B.; Zhao, J.P.; Chen, Z.P.; Zhou, G.M.; Li, F.; Cheng, H.M. Graphene anchored with $\mathrm{Co}_{3} \mathrm{O}_{4}$ nanoparticles as anode of lithium ion batteries with enhanced reversible capacity and cyclic performance. ACS Nano 2010, 4, 3187-3194. 
30. Wang, H.L.; Robinson, J.T.; Diankov, G.; Dai, H.J. Nanocrystal growth on graphene with various degrees of oxidation. J. Am. Chem. Soc. 2010, 132, 3270-3271.

31. Chen, J.K.; Sun, Z.L.; Zhu, Y.J.; Chen, N.F.; Zhou, Y.F.; Ding, J.; Chen X.H.; Chen, L.D. Top-down fabrication of nano-scaled $\mathrm{Bi}_{2} \mathrm{Se}_{0.3} \mathrm{Te}_{2.7}$ associated by electrochemical Li intercalation. Dalton Trans. 2011, 40, 340-343.

32. Cunningham, P.T.; Johnson, S.A.; Cairns, E.J. Phase equilibria in lithium-chalcogen systems. J. Electrochem. Soc. 1973, 120, 328-330.

33. Liu, S.Y.; Xie, J.; Zheng, Y.X.; Cao, G.S.; Zhu, T.J.; Zhao, X.B. Nanocrystal manganese oxide $\left(\mathrm{Mn}_{3} \mathrm{O}_{4}, \mathrm{MnO}\right)$ anchored on graphite nanosheet with improved electrochemical Li-storage properties. Electrochim. Acta 2012, 66, 271-278.

34. Pan, D.Y.; Wang, S.; Zhao, B.; Wu, M.H.; Zhang, H.J.; Wang, Y.; Jiao Z. Li storage properties of disordered graphene nanosheets. Chem. Mater. 2009, 21, 3136-3142.

35. Hummers, W.S.; Offeman, R.E. Preparation of graphitic oxide. J. Am. Chem. Soc. 1958, 80, 1339-1339.

(C) 2012 by the authors; licensee MDPI, Basel, Switzerland. This article is an open access article distributed under the terms and conditions of the Creative Commons Attribution license (http://creativecommons.org/licenses/by/3.0/). 